Article

\title{
Crooked Views and Relaxed Rules: How Teenage Boys Experience Parents' Handling of Digital Gaming
}

\author{
Mikko Meriläinen \\ Game Research Lab, Tampere University, 33100 Tampere, Finland; E-Mail: mikko.merilainen@tuni.fi
}

Submitted: 27 April 2020 | Accepted: 22 June 2020 | Published: 6 January 2021

\begin{abstract}
Digital gaming is a major part of the current media landscape. Parents employ a variety of practices, such as limiting gaming time and discussing games, when addressing their childrens' gaming. Yet, there is still a notable gaming-related generational gap between adolescents and their parents. In this qualitative study, gaming-related parenting practices and parents' and teenagers' views are examined through a thematic analysis of reports from Finnish, 16-19-year-old, active game players. The results suggest a core tension between elements of protection and understanding. Perceived parental attitudes towards gaming ranged from excessively negative to indifferent to very positive. These attitudes were not static, but instead changed according to life situations and parents' familiarity with gaming. Young game players' perceptions and views were also not uniform. Respondents indicated the need for both parental understanding of games and gaming, and parents' responsibilities in limiting gaming, particularly in the case of younger children. Implications for parenting and future research are discussed.
\end{abstract}

\section{Keywords}

digital gaming; gaming literacy; media education; parental mediation; parenting

\section{Issue}

This article is part of the issue "Games and Communication-Quo Vadis?" edited by Marko Siitonen (University of Jyväskylä, Finland), Felix Reer (University of Muenster, Germany) and Teresa de la Hera (Erasmus University Rotterdam, The Netherlands).

(C) 2021 by the author; licensee Cogitatio (Lisbon, Portugal). This article is licensed under a Creative Commons Attribution 4.0 International License (CC BY).

\section{Introduction}

Digital gaming is an established pastime globally. While enjoyed by people of all ages, digital gaming is often addressed in the context of children, adolescents, and emerging adults in both research (e.g., Brus, 2018; Chai, Chen, \& Khoo, 2011; Russell \& Johnson, 2017) and public discourse (e.g., Gregory, 2020; Stuart, 2020). This is unsurprising considering the popularity of the activity: In the author's native Finland, 36.4\% of young people under 20 report playing digital games daily, while $69.8 \%$ do so at least weekly (Kinnunen, Lilja, \& Mäyrä, 2018).

While it is a common activity, the role of digital gaming is contentious: Since the 1970s, digital gaming has been the subject of both moral panics (Pasanen, 2017) and more legitimate concerns focusing, for example, on problematic or disordered gaming (see Aarseth et al., 2017; Billieux et al., 2017), and the convergence of gaming and gambling (Macey \& Hamari, 2019). Despite digital gaming also being an activity common to adults (Entertainment software association, 2019; Kinnunen et al., 2018), studies on gaming as part of family life reveal a notable gaming-related generational gap between adolescents and their parents (e.g., Brus, 2018; Russell \& Johnson, 2017). As gaming can be an intensive, time-consuming activity, it has become a challenging parenting issue in some families (Brus, 2018; Chai et al., 2011; Russell \& Johnson, 2017).

This article explores teenaged boys' experiences of parental views and practices, as well as their own views on parenting in respect to digital gaming. This is achieved through a thematic analysis of qualitative survey reports from Finnish boys who actively play digital games. 


\section{Background}

In this study, the expressions gaming-related parenting and parenting digital game players are used interchangeably to discuss the different practices parents adopt when addressing their children's digital gaming. Despite the topicality of the issue, research on parenting adolescent digital game players, especially older adolescents, is sparse. A considerable part of the research literature has approached the subject through quantitative methods, utilizing some variant of the parental mediation model (e.g., Eklund \& Bergmark, 2013; Martins, Matthews, \& Ratan, 2017; Nikken \& Jansz, 2006), originally developed for studying television mediation (Valkenburg, Krcmar, Peeters, \& Marseille, 1999). The three practices listed in the parental mediation model, i.e., limiting gaming time or the games children are allowed to play, discussion of gaming and game content, and co-playing games with their children, are often employed by parents addressing their children's gaming (e.g., Jiow, Lim, \& Lin, 2016; Martins et al., 2017; Nielsen, Favez, Liddle, \& Rigter, 2019). Different styles of mediation may co-occur in families, with suitable methods being chosen according to the situation (Jiow et al., 2016; Nielsen et al., 2019).

There is limited qualitative research on the ways in which parents address young game players' digital gaming. This can be considered a weakness in the existing literature, as both qualitative (e.g., Kutner, Olson, Warner, \& Hertzog, 2008) and quantitative (e.g., Martins et al., 2017) approaches have revealed the subject of digital gaming, and gaming-related parenting, to be complex and nuanced. The subject lies at the intersection of three phenomena, parenting, gaming, and youth, all of which are already complex and diverse topics.

While the amount of qualitative research into gaming-related parenting is limited, a growing body exists. Enevold and Hagström (2008) have studied how mothers negotiate their own digital gaming with parenthood and gender expectations, reminding us that in the context of digital gaming parents can also perform the role of an active player, not simply that of a mediator. Furthermore, Enevold (2012), Aarsand and Aronsson (2009), Brus (2018), and Gregersen (2018) have examined how gaming is situated at home, both physically and as a part of family politics and power struggles, and how both parents and children demonstrate agency in the context of gaming.

Interviews with 12-14 year-old boys and their parents about digital gaming, conducted by Kutner's research group (Kutner et al., 2008; Olson, Kutner, \& Warner, 2008), demonstrated both parents' concerns related to gaming, and that their children accurately perceive those parental concerns. Most of the adolescents interviewed indicated that they considered their parents to be ignorant about video games, either in general terms, or in respect to their child's gaming habits. Madill's (2011) study of the ways in which parents experience and view adolescents' gaming revealed insecurities and internally conflicting views on gaming and related parenting. As in Kutner et al. (2008), parents recognized both risks and benefits in gaming, yet found it challenging to balance these in their parenting.

Russell and Johnson's (2017) study of parents of emerging adults (aged 23-25) who had been labelled as excessive gamers, highlighted the difficulties parents face when addressing gaming that they perceive as problematic-a situation made especially challenging when their children are already adults and, consequently, no longer dependent on their parents to the same degree. The lack of understanding of gaming displayed by parents in previous studies (e.g., Kutner et al., 2008; Madill, 2011) was also evident in Russell and Johnson's study.

Although an exhaustive review of qualitative research on parenting and video gaming is not possible in the confines of this article, the studies above highlight the complex interplay of gaming and domestic life, with family dynamics affecting gaming, and vice versa. Gaming at home is not contingent on the individual game player alone; instead, it is physically, mentally, and socially shaped by the home environment.

Examples from the domain of problematic digital gaming (e.g., Bax, 2016; Nielsen, 2015) have shown that qualitative approaches can illuminate crucial facets of both parent-child interaction and family dynamics, while also allowing young game players to voice their own views in research concerning them. A considerable portion of the research on young people's gaming concerns the risks involved (e.g., Choo, Sim, Liau, Gentile, \& Khoo, 2015; Festl, Scharkow, \& Quandt, 2013; Gabbiadini \& Riva, 2018), rather than exploring other facets of a common, and often important (e.g., Lenhart, Smith, Anderson, Duggan, \& Perrin, 2015) pastime. This is potentially due to a long-standing tendency to, somewhat erroneously, view youth as a period of inevitable problems, of risky behaviour, and of so-called Storm and Stress (e.g., Arnett, 1999; Collins \& Steinberg, 2008; Steinberg \& Morris, 2001).

\section{Method and Data}

This exploratory study examined teenaged game players' (aged 16-19) views and experiences of gamingrelated parenting; a qualitative approach, focusing on detailed reports from a small number of respondents, was adopted in order to better capture nuances of the phenomenon. The study was part of a larger, multimethod study (Meriläinen, 2020) that examined gaming motives and adverse consequences in addition to views on parenting.

The study addresses the following research question:

How do teenaged digital game players describe and perceive their parents' approach to digital gaming and gaming-related parenting, and how does it compare to their own views? 
By addressing this question, the study renders visible everyday interactions around digital gaming, as well as normative views young game players hold of parenting in the context of digital gaming. It adds to a limited body of research which considers young people's gaming from a perspective centred on their own views, with a focus on older adolescents.

A survey questionnaire was administered to male students $(N=22)$ participating in a voluntary course on gaming culture at a general upper secondary school in the spring of 2018. In Finland, general upper secondary school is typically attended by students aged 16 to 19 in preparation for further studies (Finnish Ministry of Education and Culture, 2020). The questionnaire consisted of background questions (age, weekly gaming time [WGT]) and four open-ended questions, while gaming times were collected in order to retain comparability with other sections of the larger study, and to ensure that the respondents could be considered active game players based on their gaming activity. The open-ended questions consisted of several sentences (e.g., "How do you think guardians should address their children's gaming? You can consider the question in regard to both your own age group and that of game players younger than you"). In addition to questions on views and experiences of game-related parenting, the questionnaire included questions on gaming motives and gaming-related adverse consequences as part of a larger study. While responses to these questions were included in the analysis, findings not related to parenting are not discussed in this article. The total size of the Finnish language data was 3613 words.

A thematic analysis, following Braun and Clarke (2006), was conducted on the data; thematic analysis is a qualitative method in which the researcher seeks to identify broader themes in data, based on either their own interpretation or existing theory. In this study, the former approach was adopted. The conducted thematic analysis was descriptive, focusing on what was explicitly said rather than possible underlying structures. Initially, I identified 110 individual codes in the data, 46 of which related to parenting. Through an iterative process, the codes were grouped into larger sub-themes, which were in turn interpreted to form broader, overarching themes.

The themes discussed in the results section explicitly concern parenting. Other important themes, addressing issues such as motives for gaming, and adverse consequences of gaming, have been discussed in a separate publication (Meriläinen, 2020).

\section{Results}

The results section is organised according to the two main themes identified: Protection, focused on limiting gaming and addressing problems; and Understanding, which addressed the need for parents to understand and accept games and gaming. Each theme is examined indi- vidually below. Example quotes have been used to illustrate the main themes and sub-themes. Quotes have been translated from Finnish by the author, and minor editing work such as grammar and punctuation, as well as clarification of some sentences, has been performed during translation. To provide context, the respondent's age is reported in parentheses after each quote, as well as their self-reported WGT.

All but one of the respondents reported playing digital games for at least two hours per week. More than half of the respondents ( $n=13$, of 22 ) reported playing over 14 hours per week on average, the average WGT for their age group in Finland being 10,8 hours per week at the time the data was gathered (Kinnunen et al., 2018).

\subsection{Protection}

The main theme Protection included the sub-themes: Rules and limits are needed, Age matters, and Problems in gaming should be addressed. These are discussed below.

\subsubsection{Rules and Limits are Needed}

Respondents both considered that parents should limit gaming in some ways and had experiences of their parents doing so. Different limits on gaming, based on time or age ratings, were usually justified by the protection point of view. Negative impacts of gaming were explicitly and implicitly discussed in many of the responses, especially in the context of younger children, and were presented as justification for limiting gaming. The subtheme indicates that the concept of limiting gaming in different ways is something that young gamers generally agree with, although not to an unlimited extent, as explored in the second sub-theme:

I think guardians should limit gaming in some way, because nothing good will come out of it if a child just plays and plays and plays. $(16,14-20 h$ WGT)

Parents should talk about gaming with their children and set rules, like that they need to do their homework before they're allowed to play, and if they're playing despite not finishing their homework, then parents should take away the controllers. If this continues, then set a rule that gaming is only allowed on weekends. The age ratings of games should also be given a look. (18, 14-20h WGT)

There must be limits, especially for preteens and small children. Otherwise gaming will get out of control and that will be reflected in poor school performance, among other things. As a child grows and understands the importance of school, they can be given more leeway with their gaming. (18, 14-20h WGT) 


\subsubsection{Age Matters}

Players were given more responsibility for their own gaming with age. As with many other parenting-related views, this was presented both as descriptive and as normative: this had been done and it should be done. The sub-theme reflects the role of development and maturation, as parents appear to acknowledge the difference between teenagers and children, and teenagers in turn wish to set themselves apart from children and young adolescents, possibly also by adopting a stance imitating that of their parents and other adults:

When I was younger (approximately 6-12 years old) I had a certain amount of "gaming time." I could get more of this gaming time if I went outside to do something else for a few hours. Nowadays my parents assume that I can limit the time I spend on gaming myself, if necessary. (18, 2-7h WGT)

When I was young, there were strict time limits set on my gaming, but nowadays I play according to my own wants....Time limits need to be set for young gamers, and [parents need to] make sure that too young players don't play too distressing games. (17, 14-20h WGT)

Before, I had a given time that I could play, but these days my parents don't restrict it in any way.... Of course it would be good to pay some attention to younger kids' gaming, but obviously I think that the gaming of my age group doesn't need to be addressed in any way. $(17,7-14$ h WGT)

\subsubsection{Problems in Gaming Should Be Addressed}

Responses included wishes for fewer restrictions to gaming, but respondents also mentioned addressing and preventing problems as being important. Addressing problems was typically seen necessary if gaming started causing problems in other areas of life. Importantly, this view did not conflict with an overall positive attitude towards gaming. Responses also revealed some of the issues teenagers identify as risks associated with gaming, such as problems related to school achievement, inadequate sleep, and negative impacts on social relationships:

If gaming starts to impede e.g., studies or friendships, I think it should/has to be reduced. $(18,2-7$ h WGT)

Guardians should adopt as positive a view of gaming as possible and allow it just like other hobbies.... Of course parents also have to take responsibility for fulfilling a child's or a youth's needs and make sure that they [children and youth] handle their responsibilities, to prevent for example marginalization or poor school performance. $(18,14-20 \mathrm{~h}$ WGT)
Parents shouldn't limit gaming, because limits invite breaking them. Parents should accept that their children are interested in games. This doesn't mean, however, that parents shouldn't monitor sleeping. If a child plays deep into the night, this should be very quickly addressed because it can become a habit. $(17,20-40 h$ WGT $)$

\subsection{Understanding}

The main theme of Understanding consisted of responses which mentioned the need for parents to understand digital gaming, as well as responses in which parents' views were criticized for a lack of understanding. The theme included sub-themes Stereotypical negativity, Gaming-positive parents, and Differing parental views.

\subsubsection{Stereotypical Negativity}

Responses in this sub-theme indicated that teenagers perceived, or assumed, parents' attitudes towards gaming as being predominantly negative, disinterested, or both. This appears to be a notable stereotype, with the assumption that parents viewed gaming as "a bogeyman," "a vice" or "a waste of time." Some responses indicated that this perception was based on personal experience, while others were more general:

My guardian views gaming with a crooked eye, like the stereotype assumes parents to do. Everything that I do wrong or skip doing is magically the fault of "video games." (17, 2-7h WGT)

Gaming should also be discussed with children, and not just from a negative perspective, but so that you have clearly set rules. Of course, every parent should also observe what kind of an effect gaming has on their child and even play together with them sometimes. $(17,20-40 \mathrm{~h}$ WGT)

Guardians should be open-minded towards gaming, and not see it as a bogeyman excluding children from society. Parents should be present in children's gaming and be interested in it, especially at a younger age [presumably the child's]. (19, 7-14h WGT)

In my opinion guardians should discuss gaming constructively, and not just set time limits and consider games a waste of time. While younger children are not as responsible as those around my age, I still think that their gaming shouldn't be limited all that much. Parents should also discuss gaming and be at least a little interested, so that gaming doesn't just feel like a vice. $(18,2-7 \mathrm{~h}$ WGT) 


\subsubsection{Gaming-Positive Parents}

There were many reports of positive interactions with parents around gaming. These reports mentioned, for example, playing games together with parents, parents supporting the respondent's gaming hobby or parents' attitudes becoming more positive with time. This contrasts directly with the previous sub-theme; despite the stereotype identified, many parents held predominantly positive views of gaming, whether grounded in their own gaming hobby, the perceived benefits of gaming, or observation of their children's gaming over the years:

My parents are really relaxed in regard to gaming. If gaming is not impacting other things in my life, such as schoolwork, I'm free to play as much as I want. My parents have supported my gaming especially when I was younger. Gaming was a hobby for me, and my parents supported me in it just as much as they did in my football playing. (19, 2-7h WGT)

When I was younger, my parents weren't fans of my gaming. They were afraid that it would disturb my schoolwork and/or friendships. Now that school is going well, my parents have started to understand my gaming and realized that gaming doesn't impact my schoolwork, at least not to any meaningful extent. My father plays FPS [first-person shooter] games occasionally, my mother plays FB [Facebook] games. $(18,14-20 h$ WGT)

We've always had a relaxed approach to gaming at home. Since I was little there have been no attempts to limit my gaming apart from age restrictions when I was younger. When I was younger, my parents played games together with me, which I think helped them better understand my gaming. These days gaming is normal in our house and my little brother has also started gaming. I see my parents adopt a similar approach as they did with me: They play games with my brother and view it as a good way to learn English. (19, 7-14h WGT)

\subsubsection{Differing Parental Views}

Two of the respondents commented that their parents have differing views on gaming from one another; in one case the respondent's mother held the more positive view, in the other case it was the father. The responses do not reveal whether parents were separated, or if the family was living together, but simply that parents endorsed different views. This theme reminds us that whether co-habiting or separated, parents are still individuals in terms of their views and parenting practices, although parents often likely seek to align the latter to some extent:
My father holds a very negative view of gaming, because he doesn't see anything beneficial in it. In contrast my mother hasn't really addressed my gaming other than by saying, that I should do something else as well. Still, my mother sees that gaming keeps me happy and that I do it with my friends. My father always makes this old classic connection: gaming is the problem that causes poor school performance. $(16,14-20 h$ WGT)

My mother's perspective is almost a polar opposite of my father's. My father loves technology and games, whereas my mother has never fully understood this interest. It's the same thing with my gaming. She was strongly against me ever gaming for more than two hours per day, and for many years she tried to get me to stop gaming. She was also very strict with age limits, and if I ever wanted to get games, I had to get them through my father. $(17,20-40 h$ WGT)

\section{Discussion}

This study examined teenaged digital game players' descriptions of how their parents addressed digital gaming, and how these descriptions compared to the teenagers' own views. In line with previous qualitative studies, results revealed a heterogenous selection of different parental practices and attitudes (e.g., Brus, 2018; Chai et al., 2011; Kutner et al., 2008). Mediation strategies outlined in previous quantitative research (e.g., Eklund \& Bergmark, 2013; Martins et al., 2017), as well as other approaches, could be identified in the data.

Two key themes, Protection and Understanding, were constructed from the responses, and formed the core of the respondents' descriptive and normative views of gaming-related parenting. Although they were two distinct themes, there was overlap: protection and risk mitigation, and understanding gaming were not seen as mutually exclusive, but instead often seen to be complementary.

Gaming-related parenting was often perceived to be reactive, focusing on the protection aspect: limiting gaming in a variety of ways rather than engaging with the activity or seeking to foster skills such as game literacy (e.g., Klimmt, 2009; Squire, 2005). Although parents' negative approach to gaming is a stereotype, the stereotype does not appear to be completely unfounded. While many of the respondents reported their parents worrying over gaming, this worry often did not translate into interest in gaming but, instead, manifested as setting various limitations on gaming. Based on teenagers' reports, in addition to the explicitly negative attitudes, there are still significant gaps in many parents' understanding of games, gaming, and gaming culture. This is similar to the results obtained by both Kutner et al. (2008) and Madill (2011) around a decade previously, suggesting that while parents' knowledge and understanding of gaming may be increasing, the situation is still far from ideal. 
Serious conflict in families over gaming (see Brus, 2018; Chai et al., 2011; Russell \& Johnson, 2017) was not present in the reports. While minor conflict situations were mentioned, these did not appear to differ from typical arguments occurring between parents and teenagers during youth (Collins \& Steinberg, 2008; Steinberg \& Morris, 2001). In contrast, several respondents mentioned their parents having a positive approach and participating in their children's gaming in different ways, such as by co-playing or helping them go to LAN parties (see also Brus, 2018). According to the respondents, some parents were active game players themselves (see Enevold \& Hagström, 2008), although this was rare.

Parents' views on gaming were often interpreted to be pragmatic, sometimes even indifferent, in situations where parents did not address gaming unless it was perceived as visibly interfering with issues such as school or sleeping patterns. Similar experiences were reported by adolescents in earlier research by Kutner et al. (2008). School performance was repeatedly raised in the responses as a source of parents' worry; sometimes parents would ascribe problems at school to gaming, a view that some of the respondents did not share. However, school disruption due to gaming was also one of the main issues the respondents considered important for parents to address, and to prevent. While there is considerable variation between individuals, moderate gaming has been associated with better school performance in Finnish youth (Meriläinen, 2020).

Parents appeared to become more accommodating of gaming as children matured, an observation in line with previous research (e.g., Eklund \& Bergmark, 2013; Shin \& Huh, 2011; cf. Brus, 2018). This is likely due to the higher degree of autonomy afforded to older teenagers (e.g., Steinberg \& Morris, 2001), as well as to parents' observations of gaming. In several respondents' interpretations, parental worry had decreased with time as no negative changes in their children were noticed, despite years of digital gaming.

The respondents' normative views of gaming-related parenting followed the two main themes discussed above. The balance between elements of the two varied, with some respondents stressing the need to understand, and others the need to protect. Individual quotes suggest that some of the respondents may have turned a descriptive account of their own experience into a normative view on parenting: if something had worked for them, it could, and possibly should, also work as a general rule. According to Hirsjärvi and Perälä-Littunen (2001), the beliefs of older children often resemble those of their parents, suggesting a transmission of beliefs from one generation to another.

It is notable that several of the respondents expressed surprisingly conservative views regarding game-related parenting, conservative in this case meaning views stricter than guidelines suggested by actors such as the APA (American Psychological Association, 2019). These views were typically brought up when dis- cussing younger children's gaming. While respondents did not explicitly mention ages, it can be assumed from the context of their answers that they meant pre-teen and younger children, approximately aged 7-12. Similar results of young game players expressing worry over younger children's gaming, but not their own, have been obtained from early adolescent respondents in previous studies (Scharrer \& Leone, 2006; Olson et al., 2008).

Strict or relaxed rules on gaming, whether descriptive or normative, did not appear to be obviously connected to reported amounts of gaming. According to the respondents, parents sometimes complained of excessive gaming despite the actual amounts of gaming being reasonably low, while some respondents who spent considerable amounts of time gaming, and held very positive views on gaming, considered limitations important. This reinforces previous findings that time spent gaming is, in itself, an insufficient measure of the role gaming plays in an individual's life, and by extension that of their family (see e.g., Brunborg, Mentzoni, \& Frøyland, 2014; Lemmens, Valkenburg, \& Peter, 2011).

\subsection{Study Limitations}

There are some limitations of the study. First, the results are based on adolescent reports, instead of parent-son dyads (cf. Kutner et al., 2008); thus, they are the respondents' perceptions and interpretations of their parents' views and motives, and as such may differ from how their parents view the situation (see Nikken \& Jansz, 2006) or the actual reality of the situation. That which a respondent considers to be an unfair and categorically negative view of gaming may, from the parent's point of view, be a lenient, if cautious, approach. In addition, there is the potential for social desirability bias to be present (see Nederhof, 1985). While respondents were assured of the confidentiality of their responses, and explicitly informed both in text and verbally that the research did not have an agenda to paint gaming as positive or negative, some respondents may have provided what they assumed to be a "correct" or desirable answer. Although the data was rich overall, a few individual responses were brief, consisting of only a few sentences.

While the course had several female students, they, as well as several male students, were unfortunately absent on the day the survey was administered, thus necessitating the focus of this study on male digital game players. As data collection occurred during the school day, and on the final session of the course, scheduling constraints prohibited a second round of data collection. Existing research shows that gender and gender expectations may considerably impact an individual's experiences of digital gaming cultures (e.g., Lopez-Fernandez, Williams, \& Kuss, 2019; Salter \& Blodgett, 2012; Taylor, Jenson, \& de Castell, 2009), and may additionally influence related parenting (Enevold \& Hagström, 2008). Gender differences have also been observed in parental influence on problematic gaming (Bonnaire \& Phan, 
2017; Choo et al., 2015). Although a meta-analysis by Endendijk, Groeneveld, Bakermans-Granenburg, and Mesman (2016) suggests minimal differences in parenting regarding control and autonomy support between boys and girls, parents' worry over gaming appears to focus on boys (e.g., Madill, 2011), implying potentially different parenting approaches based on gender. Further studies are required to explore the gaming, and gaming-related parenting, of female and non-binary game players.

The qualitative nature of the study provides detailed and contextualized data, but also limits its generalizability. This is a common feature of qualitative research (Onwuegbuzie \& Leech, 2010). The themes described in the results section, as well as the codes they consist of, are constructed by the researcher; they do not spontaneously emerge but represent the author's interpretation and abstraction (see Braun \& Clarke, 2006). Other themes could be interpreted from the same data, based on an individual researcher's interests, views, and disciplinary background, as well as the abstraction level of the themes.

The study features a small, predominantly white, group of Finnish young men attending the same general upper secondary school. Although not representative of young Finnish game players, it illustrates some of the diversity of teenage boys who play digital games, and the variety of their experiences and views of parenting. While demographic information was not collected from participants, their attendance of a general upper secondary school indicates a moderate level of academic achievement, as there are grade requirements for entrance. It should be noted, however, that the grade requirements for this individual school were low compared to city averages. In terms of interest in games and gaming cultures, the collaborating teacher responsible for the course described the respondent group as diverse, with variation in motives for participation (some were intensely interested in gaming cultures, others chose the course for schedule reasons) and engagement with course content. The written responses to the questionnaire support this observation of a diverse group of participants, with heterogenous views and experiences.

\subsection{Implications for Parenting and Future Research}

Taking the aforementioned limitations into account, this study offers new insights into how older teenagers (cf. Chai et al., 2011; Kutner et al., 2008; Olson et al., 2008) view parenting related to digital gaming: a qualitative approach enabled teenaged game players to voice their views on an issue that directly concerns them. In previous research, qualitative approaches have allowed young game players to challenge prevailing narratives about issues such as problematic gaming (e.g., Brus, 2018; Nielsen, 2015).

Results suggest that tension between protecting youth and children from perceived risks related to gam- ing, and understanding games, gaming, and gaming cultures, appears to lie at the core of parenting related to digital gaming. This tension was apparent both in the teenaged respondents' descriptions and perceptions of parenting, and in their normative views. While protection and limiting gaming, especially in the case of younger children, was viewed as necessary, the respondents also considered parents' understanding of gaming to be important. Parents' perceived lack of understanding, as well as their negative attitudes, were seen to be problems.

Rather than framing gaming as primarily positive or negative, an approach common in media discourses of gaming (Kümpel \& Haas, 2016), many of the reports from the young respondents were nuanced, and the respondents perceived their understanding of the phenomenon to be more advanced than that of their parents. As data in this study and previous research (Bax, 2016; Brus, 2018; Madill, 2011; Nielsen, 2015; Shin \& Huh, 2011) inform us, tension and conflict over gaming may result from the fact that parents have difficulties understanding or accepting gaming; a considerable disconnect between parents' and their children's understanding of gaming still exists in many families. Although adults make up a large portion of digital game players (Entertainment software association, 2019; Kinnunen et al., 2018), it is apparent that this does not mean that most parents are familiar with games and gaming, or that they can address them constructively in their parenting. Also, as evidenced by some of the teenagers' views, understanding of, and participating in, gaming culture does not automatically equate to a particularly understanding approach to parenting digital game players.

While the generation gap regarding gaming is mentioned (e.g., Squire, 2005) in existing literature on games and gaming literacy, the importance of parents' gaming literacy is addressed to a very limited extent, with the focus mostly on formal education contexts (e.g., Apperley \& Beavis, 2013; Buckingham \& Burn, 2007; Squire, 2005; cf. Chuang \& Tsai, 2015). This can be considered surprising, as demonstrated by both the current study and existing research (e.g., Brus, 2018; Li, Lo, \& Cheng, 2018; Su et al., 2018), while they are living at home, young people's gaming is closely tied to the relationship between them and their parents. It follows that instead of focusing only on youth or their parents in isolation, families should be examined as a system of interconnected actors (see Aarsand \& Aronsson, 2009; Brus, 2018; Steinkuehler, 2015).

Despite negative aspects commonly attributed to both digital gaming (Pasanen, 2017) and adolescence (Arnett, 1999), parenting adolescent digital game players did not appear to be a continuous, inevitable struggle, nor were the opinions of teenagers and their parents in polar opposition (see also Kutner et al., 2008). Although some respondents reported minor conflict around gaming, serious incidents were not present in the data. In most responses, digital gaming was framed as an 
everyday activity which did not trouble parents as long as it did not interfere with other life areas, especially health and schoolwork. This finding is supported by previous research (e.g., Chai et al., 2011; Madill, 2011; cf. Bax, 2016; Brus, 2018), although the possibility of either an especially conflict-free sample or gaps in reporting cannot be ruled out.

Both this study and much of the literature discussed previously suggest that parents' approaches to parenting digital game players are mainly formed around protection and reactive action, rather than understanding. This is understandable, for example as a result of parents' limited resources, fears, and uncertainties (Madill, 2011), negative media portrayals of gaming (Kümpel \& Haas, 2016; Pasanen, 2017), and actualized adverse consequences from gaming (e.g., Brunborg et al., 2014). However, the approach appears to have limited impact in reducing problems associated with gaming (Choo et al., 2015; Meriläinen, 2020), and may even add to them by increasing family tension and conflict (Madill, 2011; Nielsen, 2015; Shin \& Huh, 2011). More research, both qualitative and quantitative, is needed to discern the motives and causes leading to different approaches to parenting digital game play, as well as their impact on gaming-related adverse consequences and family dynamics.

To keep gaming-related parenting from becoming merely reactive and protection-focused, parents might adopt a more active and conscious approach, one grounded in an understanding of both gaming as a phenomenon, and the personal and family dynamics involved. Based on teenaged game players' experiences, this could constitute a viable means of alleviating parental concern, helping to bridge the gamingrelated generation gap and reducing conflict around gaming, thus promoting well-being in both parents and youth. Gaming-specific media education with the goal of increasing parents' game and gaming literacy (e.g., Klimmt, 2009; Meriläinen, 2020; Squire, 2005) has been suggested as a way to address this (Meriläinen, 2020; Schott, 2010), an argument that finds support in this study (see also Madill, 2011).

This study adds to a body of research which underlines the need to move discussion and parenting practice away from simplistic approaches based on limiting socalled screen time and, instead, towards a more nuanced view of youth well-being and participation in digital cultures (see Blum-Ross \& Livingstone, 2018). Youth reports suggest that the broadly criticized idea of young people as passive media victims (Hobbs, 2011) still lingers in parenting practices. Contrary to this view, many of the respondents held nuanced and critical views on gaming and related parenting. These views are best described as responsible, and in some cases even conservative.

The dual aspects of protection and understanding raised by the young respondents strongly suggest that gaming-related parenting should involve more than just protection and setting limits, namely the dimension of seeking to understand and support gaming, and by extension youth autonomy and agency. This approach does not mean that parents should forgo the protection dimension of gaming-related parenting, which was also considered important by young game players, but rather that protection should be one aspect of a broader whole, not its entirety. The result reflects a broader discussion on gaming-related parenting and gaming in general. The needs to protect and to understand have been previously highlighted by both parents (e.g., Madill, 2011) and researchers (e.g., Klimmt, 2009; Meriläinen, 2020), and suggest a key source of tension not only in the context of parenting, but for example in the ongoing discussion of problematic or disordered gaming (see Aarseth et al., 2017; Billieux et al., 2017). While this tension has been explored previously (e.g., Brus, 2018; Madill, 2011), more empirical research is needed to discern how this tension is perceived and negotiated in both everyday domestic situations and in gaming cultures more broadly, and how it is affected by variables such as power dynamics and gaming behaviour.

As a final note, gaming-related parenting, as well as adolescent gaming in general, has received limited attention in game studies, despite the discipline's explicit focus on digital games and gaming (Aarseth, 2001). Considering that digital gaming is a highly prevalent activity among teenagers, and that parents considerably shape youth involvement in gaming, this can be seen as a deficiency in the literature. With the prevalence of problem-focused research and the dearth of studies grounded in nuanced understanding of gaming cultures, there is a risk of research consciously and unconsciously framing youth gaming as primarily a risk for both the players and their parents, thus reinforcing existing negative narratives.

\section{Conclusions}

The study suggests a core tension between elements of protection and understanding in teenaged game players' descriptions and normative views of gaming-related parenting. Considerable variance in both youth views and reported parenting practices highlight the importance of qualitative approaches when addressing the subject. Teenaged boys' digital gaming, and parenting related to it, are both heterogenous phenomena, contingent on a wide range of situational variables. This complexity should be acknowledged when addressing games and parenting, whether conducting research, devising guidelines, or engaging in public discourse.

\section{Acknowledgments}

The author wishes to thank Professor Markku Hannula and Associate Professor Petri Lankoski for their feedback during the research process, as well as the reviewers for their valuable comments. The research was partly funded by the Strategic Research Council 
project Growing Mind: Educational Transformations for Facilitating Sustainable Personal, Social, and Institutional Renewal in the Digital Age (grant \#326603), and a grant from the University of Helsinki.

\section{Conflict of Interests}

The author declares no conflict of interests.

\section{References}

Aarsand, P. A., \& Aronsson, K. (2009). Gaming and territorial negotiations in family life. Childhood, 16(4), 497-517. https://doi.org/10.1177/090756820 9343879

Aarseth, E. (2001). Computer game studies, year one. Game Studies, 1(1).

Aarseth, E., Bean, A. M., Boonen, H., Colder Carras, M., Coulson, M., Das, D., ... Van Rooij, A. J. (2017). Scholars' open debate paper on the World Health Organization ICD-11 Gaming Disorder proposal. Journal of Behavioral Addictions, 6(3), 267-270. https://doi. org/10.1556/2006.5.2016.088

American Psychological Association. (2019). Digital guidelines: Promoting healthy technology use for children. Apa.org. Retrieved from https://www. apa.org/topics/healthy-technology-use-children

Apperley, T., \& Beavis, C. (2013). A model for critical games literacy. E-Learning and Digital Media, 10(1). https://doi.org/10.2304/elea.2013.10.1.1

Arnett, J. J. (1999). Adolescent storm and stress, reconsidered. American Psychologist, 54(5), 317-326.

Bax, T. (2016). "Internet Gaming Disorder" in China: Biomedical sickness or sociological badness? Games and Culture, 11(3), 233-255. https://doi.org/ $10.1177 / 1555412014568188$

Billieux, J., King, D. L., Higuchi, S., Achab, S., BowdenJones, H., Hao, W., . . Poznyak, V. (2017). Functional impairment matters in the screening and diagnosis of gaming disorder: Commentary on-Scholars' open debate paper on the World Health Organization ICD-11 Gaming Disorder proposal (Aarseth et al.). Journal of Behavioral Addictions, 6(3), 285-289. https://doi.org/10.1556/2006.6.2017.036

Blum-Ross, A., \& Livingstone, S. (2018). The trouble with "screen time" rules. In G. Mascheroni, C. Ponte, \& A. Jorge (Eds.), Digital parenting: The challenges for families in the digital age (pp. 179-187). Göteborg: Nordicom.

Bonnaire, C., \& Phan, O. (2017). Relationships between parental attitudes, family functioning and Internet gaming disorder in adolescents attending school. Psychiatry Research, 255, 104-110. https://doi.org/ 10.1016/j.psychres.2017.05.030

Braun, V., \& Clarke, V. (2006). Using thematic analysis in psychology. Qualitative Research in Psychology, 3(2), 77-101. https://doi.org/10.1191/ 1478088706qp063oa
Brunborg, G. S., Mentzoni, R. A., \& Frøyland, L. R. (2014). Is video gaming, or video game addiction, associated with depression, academic achievement, heavy episodic drinking, or conduct problems? Journal of Behavioral Addictions, 3(1), 27-32. https://doi.org/ 10.1556/JBA.3.2014.002

Brus, A. (2018). Generagency and problem gaming as stigma. In A. M. Thorhauge, A. Gregersen, \& J. Enevold (Eds.), What's the problem in problem gaming? Nordic research perspectives (pp. 51-63). Göteborg: Nordicom.

Buckingham, D., \& Burn, A. (2007). Game literacy in theory and practice. Journal of Educational Multimedia and Hypermedia, 16(3), 323-349.

Chai, S. L., Chen, V. H.-H., \& Khoo, A. (2011). Social relationships of gamers and their parents. ProcediaSocial and Behavioral Sciences, 30, 1237-1241. https://doi.org/10.1016/j.sbspro.2011.10.239

Choo, H., Sim, T., Liau, A. K. F., Gentile, D. A., \& Khoo, A. (2015). Parental influences on pathological symptoms of video-gaming among children and adolescents: A prospective study. Journal of Child and Family Studies, 24(5), 1429-1441. https://doi.org/ 10.1007/s10826-014-9949-9

Chuang, T.-Y., \& Tsai, C.-M. (2015). Forecast the scarcity of game generation: Digital game literacy. In T.-B. Lin, V. Chen, \& C. Chai (Eds.), New media and learning in the 21st century: A socio-cultural perspective (pp. 109-128). Singapore: Springer.

Collins, W. A., \& Steinberg, L. (2008). Adolescent development in interpersonal context. In W. Damon \& R. Lerner (Eds.), Child and adolescent development: An advanced course (pp. 551-592). Hoboken, NJ: Wiley.

Eklund, L., \& Bergmark, K. H. (2013). Parental mediation of digital gaming and internet use. In G. N. Yannakakis, E. Aarseth, K. Jørgensen, \& J. C. Lester (Eds.), Proceedings of the 8th international conference on the foundations of digital games (FDG 2013) (pp. 63-70). Santa Cruz, CA: Society for the Advancement of the Science of Digital Games.

Endendijk, J. J., Groeneveld, M. G., BakermansGranenburg, M. J., \& Mesman, J. (2016). Genderdifferentiated parenting revisited: Meta-analysis reveals very few differences in parental control of boys and girls. PLoS One, 11(7), e0159193. https://doi.org/10.1371/journal.pone.0159193

Enevold, J. (2012). Domesticating play, designing everyday life: The practice and performance of family, gender, and gaming. In R. Koskimaa, F. Mäyrä, \& J. Suominen (Eds.), Proceedings of DiGRA Nordic 2012 Conference: Local and global-Games in culture and society. Tampere: University of Tampere and Digital Games Research Association DiGRA.

Enevold, J., \& Hagström, C. (2008). My momma shoots better than you! Who is the female gamer? In S. Mosberg Iversen (Ed.), Proceedings of the [player] conference (pp. 144-167). Copenhagen: IT University of Copenhagen. 
Entertainment software association. (2019). 2019 Essential facts about the computer and video game industry. Washington, DC: Entertainment software association. Retrieved from https://www.theesa. com/wp-content/uploads/2019/05/2019-EssentialFacts-About-the-Computer-and-Video-GameIndustry.pdf

Festl, R., Scharkow, M., \& Quandt, T. (2013). Problematic computer game use among adolescents, younger and older adults. Addiction, 108(3), 592-599. https:// doi.org/10.1111/add.12016

Finnish Ministry of Education and Culture. (2020). General upper secondary education. Ministry of Education and Culture. Retrieved from https://minedu.fi/ en/general-upper-secondary-education

Gabbiadini, A., \& Riva, P. (2018). The lone gamer: Social exclusion predicts violent video game preferences and fuels aggressive inclinations in adolescent players. Aggressive Behavior, 44(2), 113-124. https://doi. org/10.1002/ab.21735

Gregersen, A. (2018). Games between family, homework, and friends. In A. M. Thorhauge, A. Gregersen, \& J. Enevold (Eds.), What's the problem in problem gaming? Nordic research perspectives (pp. 35-49). Göteborg: Nordicom.

Gregory, S. (2020, April 22). Don't feel bad if your kids are gaming more than ever. In fact, why not join them? Time. Retrieved from https://time.com/5825214/ video-games-screen-time-parenting-coronavirus

Hirsjärvi, S., \& Perälä-Littunen, S. (2001). Parental beliefs and their role in child-rearing. European Journal of Psychology of Education, 16(1), 87-116.

Hobbs, R. (2011). The state of media literacy: A response to Potter. Journal of Broadcasting \& Electronic Media, 55(3), 419-430. https://doi.org/10.1080/08838151. 2011.597594

Jiow, H. J., Lim, S. S., \& Lin, J. (2016). Level up! Refreshing parental mediation theory for our digital media landscape. Communication Theory, 27(3), 309-328. https://doi.org/10.1111/comt.12109

Kinnunen, J., Lilja, P., \& Mäyrä, F. (2018). Pelaajabarometri 2018: Monimuotoistuva mobiilipelaaminen [Player barometer 2018: Diversifying mobile gaming] (TRIM Research Reports No. 28). Tampere: University of Tampere. Retrieved from http://urn.fi/ URN:ISBN:978-952-03-0870-4

Klimmt, C. (2009). Key dimensions of contemporary video game literacy: Towards a normative model of the competent digital gamer. Eludamos, 3(1), 23-31.

Kümpel, A. S., \& Haas, A. (2016). Framing gaming: The effects of media frames on perceptions of game(r)s. Games and Culture, 11(7/8), 720-744. https://doi. org/10.1177/1555412015578264

Kutner, L. A., Olson, C. K., Warner, D. E., \& Hertzog, S. M. (2008). Parents' and sons' perspectives on video game play: A qualitative study. Journal of Adolescent Research, 23(1), 76-96. https://doi.org/ $10.1177 / 0743558407310721$
Lemmens, J. S., Valkenburg, P. M., \& Peter, J. (2011). Psychosocial causes and consequences of pathological gaming. Computers in Human Behavior, 27, 144-152. https://doi.org/10.1016/j.chb.2010.07.015

Lenhart, A., Smith, A., Anderson, M., Duggan, M., \& Perrin, A. (2015). Teens, technology \& friendships. Pew Research Center. Retrieved from http://www. pewinternet.org/2015/08/06/teens-technologyand-friendships

Li, A., Lo, B. C., \& Cheng, C. (2018). It is the family context that matters: Concurrent and predictive effects of aspects of parent-child interaction on video gamingrelated problems. Cyberpsychology, Behavior, and Social Networking, 21(6), 374-380. https://doi.org/ 10.1089/cyber.2017.0566

Lopez-Fernandez, O., Williams, A. J., \& Kuss, D. J. (2019). Measuring female gaming: Gamer profile, predictors, prevalence, and characteristics from psychological and gender perspectives. Frontiers in Psychology, 10. https://doi.org/10.3389/fpsyg.2019.00898

Macey, J., \& Hamari, J. (2019). Esports, skins and loot boxes: Participants, practices and problematic behaviour associated with emergent forms of gambling. New Media and Society, 21(1), 20-41. https://doi.org/ $10.1177 / 1461444818786216$

Madill, L. (2011). Scripting their stories: Parents' experiences with their adolescents and video games (Unpublished Doctoral dissertation). University of Victoria, Victoria, Canada. Retrieved from https:// dspace.library.uvic.ca/bitstream/handle/1828/ 3253/Madill_Leanna_PhD_2011.pdf?sequence= 1\&isAllowed=y

Martins, N., Matthews, N. L., \& Ratan, R. A. (2017). Playing by the rules: Parental mediation of video game play. Journal of Family Issues, 38(9), 1215-1238. https://doi.org/10.1111/comt.1210910.1177/ $0192513 \times 15613822$

Meriläinen, M. (2020). Kohti pelisivistystä: Nuorten digitaalinen pelaaminen ja pelihaitat kotien kasvatuskysymyksenä [Towards being gaming literate: Youth digital gaming and adverse consequences as a parenting issue] (Helsinki Studies in Education No. 66). Helsinki: University of Helsinki. Retrieved from https://helda.helsinki.fi/handle/10138/309143

Nederhof, A. J. (1985). Methods of coping with social desirability bias: A review. European Journal of Social Psychology, 15(3), 263-280. https://doi.org/ 10.1002/ejsp.2420150303

Nielsen, P., Favez, N., Liddle, H., \& Rigter, H. (2019). Linking parental mediation practices to adolescents' problematic online screen use: A systematic literature review. Journal of Behavioral Addictions, 8(4), 649-663. https://doi.org/10.1556/2006.8.2019.61

Nielsen, R. K. L. (2015). Turning data into people: Player perspectives on game addiction. In D. Brown (Ed.), 2015 International conference on interactive technologies and games (pp. 76-83). https://doi.org/ 10.1109/iTAG.2015.17 
Nikken, P., \& Jansz, J. (2006). Parental mediation of children's videogame playing: A comparison of the reports by parents and children. Learning, Media and Technology, 31(2), 181-202. https://doi.org/ $10.1080 / 17439880600756803$

Olson, C. K., Kutner, L. A., \& Warner, D. E. (2008). The role of violent video game content in adolescent development: Boys' perspectives. Journal of Adolescent Research, 23(1), 55-75. https://doi.org/ $10.1177 / 0743558407310713$

Onwuegbuzie, A. J., \& Leech, N. L. (2010). Generalization practices in qualitative research: A mixed methods case study. Quality \& Quantity, 44, 881-892. https:// doi.org/10.1007/s11135-009-9241-z

Pasanen, T. (2017). Beyond the pale: Gaming controversies and moral panics as rites of passage (Jyväskylä studies in humanities No. 323). Jyväskylä: University of Jyväskylä. Retrieved from http://urn.fi/URN:ISBN: 978-951-39-7152-6

Russell, L. L. H., \& Johnson, E. I. (2017). Parenting emerging adults who game excessively: Parents' lived experiences. Issues in Mental Health Nursing, 38(1), 66-74. https://doi.org/10.1080/01612840. 2016.1253808

Salter, A., \& Blodgett, B. (2012). Hypermasculinity \& dickwolves: The contentious role of women in the new gaming public. Journal of Broadcasting \& Electronic Media, 56(3), 401-416. https://doi.org/10.1080/ 08838151.2012.705199

Scharrer, E., \& Leone, R. (2006). I know you are but what am I? Young people's perceptions of varying types of video game influence. Mass Communication \& Society, 9(3), 261-286. https://doi.org/10.1207/ s15327825mcs0903_1
Schott, G. (2010). Parents and gaming literacy. Wellington: Office of Film and Literature Classification.

Shin, W., \& Huh, J. (2011). Parental mediation of teenagers' video game playing: Antecedents and consequences. New Media \& Society, 13(6), 945-962. https://doi.org/10.1177/1461444810388025

Squire, K. D. (2005). Toward a media literacy for games. Telemedium, 52(1/2), 9-15.

Steinberg, L., \& Morris, A. S. (2001). Adolescent development. Annual Review of Psychology, 52(83), 83-110. https://doi.org/10.1146/annurev.psych.52.1.83

Steinkuehler, C. (2015). Parenting and video games. Journal of Adolescent and Adult Literacy, 59(4), 357-361. https://doi.org/10.1002/jaal.455

Stuart, K. (2020, January 10). Putting controls on your kids' gaming is a key part of being a parent. The Guardian. Retrieved from https://www.theguardian. com/games/2020/jan/10/putting-controls-on-yourkids-gaming-is-a-key-part-of-being-a-parent

Su, B., Yu, C., Zhang, W., Su, Q., Zhu, J., \& Jiang, Y. (2018). Father-child longitudinal relationship: Parental monitoring and internet gaming disorder in Chinese adolescents. Frontiers in Psychology, 9(95). https://doi. org/10.3389/fpsyg.2018.00095

Taylor, N., Jenson, J., \& de Castell, S. (2009). Cheerleaders/booth babes/Halo hoes: Pro-gaming, gender and jobs for the boys. Digital Creativity, 20(4), 239-252. https://doi.org/10.1080/1462626090329032

Valkenburg, P. M., Krcmar, M., Peeters, A. L., \& Marseille, N. S. (1999). Developing a scale to assess three styles of television mediation: "Instructive mediation," "restrictive mediation," and "social coviewing." Journal of Broadcasting \& Electronic Media, 43(1), 52-66. https://doi.org/10.1080/08838159909364474

\section{About the Author}

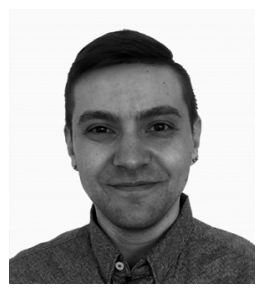

Mikko Meriläinen is a Postdoctoral Researcher at Tampere University Game Research Lab, currently working in the Centre of Excellence in Game Culture Studies, funded by the Academy of Finland. In his work, Meriläinen is currently focusing on questions of youth gaming cultures, gaming-related parenting, game jam learning, and miniaturing. 